\title{
COVID-19, other zoonotic diseases and wildlife conservation
}

\author{
Carlos Santana ${ }^{1}$ (D
}

Received: 15 August 2020 / Accepted: 29 September 2020 / Published online: 8 October 2020 (C) Springer Nature Switzerland AG 2020

\begin{abstract}
Many experts have warned that environmental degradation is increasing the likelihood of future pandemics like COVID-19, as habitat loss and poaching increase close contact between wildlife and people. This fact has been framed as a reason to increase wildlife conservation efforts. We have many good reasons to step up conservation efforts, but arguments for doing so on the basis of pandemic prevention are rhetorically, ethically, and empricially flawed.
\end{abstract}

The COVID-19 pandemic is exceptional in its impact, but as a zoonotic emerging infectious disease (EID), it is anything but unusual. In fact, the majority of EIDs originate in non-human animals, and since the 1940s the frequency of EIDs has trended upward (Jones et al. 2008). ${ }^{1}$ Since EIDs like Ebola, SARS, and COVID19 cause incredible harm, and since the risk of EIDs may be increased by global environmental change (ibid), a plethora of voices have argued that the risk of future pandemics provides a compelling reason to engage in additional wildlife conservation. Most prominently, activists and politicians have called for bans on wildlife trafficking and the sale of terrestrial wildlife in so-called 'wet markets,' as a bipartisan group of American political representatives did in a letter to the director of the World Health Organization (Booker et al. 2020). Some researchers have argued for even stronger conservation measures, arguing that the economic costs of pandemics justify scaling back economic development, since excessive development raises the risk of future pandemics (Di Marco et al. 2020).It would be a nice silver lining if one

\footnotetext{
1 This note belongs to the Topical Collection "Seeing Clearly Through COVID-19: Current and future questions for the history and philosophy of the life sciences", edited by G. Boniolo and L. Onaga.
}

Carlos Santana

c.santana@utah.edu

1 Department of Philosophy, University of Utah, Salt Lake City, USA 
response to the current pandemic was increased support for wildlife conservation. In this note, however, I'll highlight the ways in which these calls for conservation may backfire, could be racist and colonialist, and are empirically suspect.

Society has long recognized the risk of zoonotic disease, but policymakers have rarely treated this risk as reason to protect wildlife. On the contrary, animal-borne disease is usually seen as a reason to eliminate wildlife, as attested by widespread and ongoing culls of bats, rodents, wild ungulates, and other organisms known to transmit disease to humans and livestock. Our most up-to-date science suggest that culls are often counterproductive, and can increase transmission rates (Streicker et al. 2012) as well as foster emergence of novel viral strains (Turmelle and Olival 2009). Policy, unfortunately, isn't beholden to the science, and wildlife elimination remains the standard approach to mitigating disease risk. Emphasizing the zoonotic origins of COVID-19 is therefore less likely to lead to stronger conservation policies than it is to lead to accelerated reduction in wildlife populations.

The focus of conservation discussion surrounding COVID-19 is also hypocritical at best, and possibly outright racist. The current crisis has seen a plethora of calls to ban bushmeat and related forms of wildlife trade in order to prevent EIDs, but I'm aware of no significant political figure calling for restricting industrial animal agriculture for the same reason. But livestock, especially livestock kept in the unsanitary conditions of concentrated feeding operations (CAFOs), are on a par with wild animals as a source of EIDs: "the same economy-of-scale efficiencies that allow CAFOs to produce affordable meat for so many consumers also facilitate the mutation of viral pathogens into novel strains" (Schmidt 2009). Moreover, overuse of antibiotics in CAFOs increases the likelihood that EIDs originating in them will be antibiotic resistance. This is why some epidemiologists think that " $[\mathrm{t}]$ he best defense against pandemics of Emerging Infectious Diseases (EIDs) is the constant monitoring of CAFOs" (Hollenbeck 2016). To suggest that we avert future pandemics by suppressing a form of meat production most common in the developing world, without also suppressing the equally dangerous form of meat production common in wealthy nations, is to reenact the neocolonial errors that have long plagued conservation activity. Using the COVID-19 crisis to argue for wildlife conservation without also targeting animal agriculture in wealthy countries is hypocritical and unjust.

A final problem with arguing from pandemics to conservation is that the conservation arguments usually emphasize increased human-wildlife interaction, when human-human interaction is the key factor in the increasing rate of epidemics and pandemics. Increased human-wildlife contact due to habitat destruction and poaching may play a role in the initial emergence of EIDs, but whether these diseases become serious outbreaks depends largely on demographic factors. The increasing number of epidemics and pandemics is largely a result of human population growth, denser settlement, and increased migration and travel (Ahmed et al. 2019), and epidemic severity is correlates with poverty (Sahasranaman and Jensen 2020). In other words, conservation action may decrease the number of new diseases which emerge, but it is demography which governs the number of epidemics and pandemics.

In summary, the way activists and politicians have been using the COVID19 pandemic to argue for wildlife conservation is empirically suspect, since the important levers to pull on in pandemic prevention are demographic. It is ethically 
suspect, since it places burdens on the developing world but not equally warranted burdens on wealthy nations. And it is rhetorically suspect, since it lends itself to being hijacked in favor of wildlife culling. The current pandemic may lend itself to a good argument for wildlife conservation, but the arguments we're currently hearing aren't it.

\section{References}

Ahmed, S., Dávila, J. D., Allen, A., Haklay, M., Tacoli, C., \& Fèvre, E. M. (2019). Does urbanization make emergence of zoonosis more likely? Evidence, myths and gaps. Environment and urbanization, 31(2), 443-460.

Booker, C., Graham, L, Quigley, M., \& McCaul, M. (2020, April 8). Open letter to directors general of world health agencies. Congress of the United States. https://www.booker.senate.gov/imo/media/ doc/04.08.20_Booker_Graham_Quigley_McCaul_Final\%2520sBlock.pdf

Di Marco, M., Baker, M. L., Daszak, P., De Barro, P., Eskew, E. A., Godde, C. M., et al. (2020). Opinion: Sustainable development must account for pandemic risk. Proceedings of the National Academy of Sciences, 117(8), 3888-3892.

Hollenbeck, J. E. (2016). Interaction of the role of concentrated animal feeding operations (CAFOs) in emerging infectious diseases (EIDS). Infection, Genetics and Evolution, 38, 44-46.

Jones, K. E., Patel, N. G., Levy, M. A., Storeygard, A., Balk, D., Gittleman, J. L., et al. (2008). Global trends in emerging infectious diseases. Nature, 451(7181), 990-993.

Sahasranaman, A., Jensen, H. J. (2020). Poverty in the time of epidemic: A modelling perspective. arXiv: 2004.08653 [physics.soc-ph]

Schmidt, C. W. (2009). Swine CAFOs \& novel H1N1 flu: Separating facts from fears. Environmental Health Perspectives, 117, A394-A401.

Streicker, D. G., Recuenco, S., Valderrama, W., Gomez Benavides, J., Vargas, I., et al. (2012). Ecological and anthropogenic drivers of rabies exposure in vampire bats: Implications for transmission and control. Proceedings of the Royal Society B: Biological Sciences, 279(1742), 3384-3392.

Turmelle, A. S., \& Olival, K. J. (2009). Correlates of viral richness in bats (order Chiroptera). EcoHealth, $6(4), 522-539$.

Publisher's Note Springer Nature remains neutral with regard to jurisdictional claims in published maps and institutional affiliations. 